\title{
A Puzzle About Proportionality
}

\author{
David Alm 1
}

Published online: 19 December 2017

(C) The Author(s) 2017. This article is an open access publication

\begin{abstract}
The paper addresses a puzzle about the proportionality requirement on self-defense due to L. Alexander. Indirectly the puzzle is also relevant to the proportionality requirement on punishment, insofar as the right to punish is derived from the right to self-defense. Alexander argues that there is no proportionality requirement on either self-defense or punishment, as long as the aggressor/offender has been forewarned of the risk of a disproportional response. To support his position Alexander appeals to some puzzle cases, challenging us to explain why the requirement applies in some of them when it clearly does not in others. The paper responds to his challenge by answering two questions: why does the proportionality requirement exist in the first place, and when does it apply? The paper argues that the requirement holds because of our need to protect our rights from violation, and that it applies to cases where the person defending his rights counts as having imposed a cost on one of the offender's options. An account is offered of when such cost imposition occurs.
\end{abstract}

Keywords Self-defense · Punishment · Rights · Proportionality

It is a common belief that our permission to cause harm in self-defense is subject to a proportionality requirement: self-defensive harm must not be excessive relative to the harm or wrong it prevents (though what counts as 'excessive' is to some extent controversial and certainly varies with circumstances). While philosophers in recent years have had a great deal to say about self-defense generally, and the proportionality requirement in particular, this paper concerns an issue that has not

David Alm

David.Alm@fil.lu.se

1 Department of Philosophy, University of Lund, P.O. Box 192, 22100 Lund, Sweden 
received much attention. It was raised many years ago by Lawrence Alexander. Let me now describe the issue and then say something about its implications.

Consider cases in which one person, the offender, threatens to inflict wrongful harm on another person, the defender, and it is possible for the latter to prevent this harm by himself harming the offender. Alexander denies that such harm could be impermissible because disproportionate, when the offender has been warned in advance of the risk he faces. In other words, the proportionality requirement simply does not apply in such cases-though Alexander concedes that it does apply absent such a warning $(1980,1986,1991)$.

In arguing for his claim, Alexander's main strategy is in effect the following. ${ }^{1}$ (I will consider a possible subsidiary argument in 'The Responsibility Argument' section.) He first considers cases in which the defender exploits an independently existing danger to prevent the offender from wrongfully harming the defender. Alexander mentions several cases of this type, but in what follows I will be referring to this one (henceforth: Tank 1): the defender throws his water-proof watch into a shark tank to prevent the offender from stealing it (1986, p. 181n8). In this case, Alexander holds, throwing the watch into the tank is permissible, even granting (as I will, at least if the attempted theft proves fatal) that the harm involved is great enough relative to the threatened wrong to fall foul of the proportionality requirement, if the latter applies at all in the situation. As a second step Alexander contends that, if we share his view of Tank 1, we should also agree that it is permissible for the defender to create the same danger himself to prevent the same harm. Thus, if it is permissible to throw the watch into a tank already containing sharks, it should be equally permissible to put sharks into a tank already containing the watch: no proportionality requirement applies to this case either. Call it Tank 2. If we disagree, Alexander challenges us to spot the relevant difference between the cases. If we agree, we have arguably already abandoned the proportionality requirement, at least on the assumption that the purpose of putting sharks in the tank was simply to protect the watch. It is possible to press on with further cases that make the conflict with the requirement more vivid, but it is precisely the move from Tank 1 to Tank 2 that strikes me as decisive. (I will return to this point later. For now I will grant it.) Once we have conceded that the proportionality requirement does not apply in Tank 2, I will grant that we cannot explain why it does not apply in these other cases either.

The puzzle of proportionality stems from the two Tank cases: how do we distinguish them? If the proportionality requirement does not apply in Tank 1 (meaning that the defender in that case acts permissibly), but does apply in Tank 2 (meaning that the defender in that case acts impermissibly), how do we show that? To my knowledge, no sustained effort to solve the puzzle exists in the literature. ${ }^{2}$ The purpose of this paper is to fill that hole by showing how to distinguish the two

\footnotetext{
${ }^{1}$ See (1980, pp. 209-211), and (1991, pp. 324f). Alexander never explicitly mentions the distinction between creating new dangers and exploiting existing ones, but at one place (1991, p. 325n7) he recognizes that in cases of the former type the defender 'adds a new danger to the world'.

2 There are very brief discussions by Quinn, (1985, pp. 346-347n27) and Nino (1986). I will address the latter in 'When Does the Proportionality Requirement Apply?' section. Farrell (1990, p. 305n) dismisses Alexander's view without argument as 'very odd'.
} 
cases above. ${ }^{3}$ My working hypothesis is that a solution to the puzzle presupposes a clear view of why the proportionality requirement is supposed to apply in the first place, when it does. 'Proportionality and Authority' section is devoted to that question. In particular, I will argue that the requirement applies because acts of creating protective actions, such as those in the Tank cases, which impose costs on other people's options, are justified by their protecting rights, and that rights come in different strengths, which answer to different levels of cost permissibly imposed. I then turn in 'The Responsibility Argument' section to the notion of responsibility, which I believe is important to Alexander's view, and criticize an argument for that view that makes central use of the notion. Finally, I show in 'When Does the Proportionality Requirement Apply?' section when, or to which actions, the proportionality requirement applies, and so how to distinguish the two Tank cases. In particular, I will argue (a) that when the offender has not been warned of the risk of a disproportionate response (and the defender is therefore responsible for the offender's harm), the requirement does apply (as Alexander would agree), but (b) when the offender has been warned (and is therefore, perhaps, himself responsible for the harm he suffers) the requirement applies if and only if the defender has imposed a cost on one of the offender's options. The proportionality of this cost is then measured against the strength of the right its imposition protects. Further, the defender's action counts as imposing a cost on an (independently available) option of the offender's just in case it makes it the case that the offender's choosing the option in question would cause harm (or risk of harm) to the offender.

Alexander usually puts forward his claim not as one about self-defense, except implicitly, but rather as one about punishment. ${ }^{4}$ (This probably helps explains the fact, noted above, that self-defense theorists have given Alexander's argument scant attention.) In the papers I have cited he advocates the so-called self-defense justification of punishment, according to which the right to punish is derived from the right to self-defense..$^{5}$ But, he argues, if we may defend ourselves disproportionately, provided we give prior warning, the self-defense justification implies that punishment is not subject to any proportionality requirement, either. After all,

\footnotetext{
${ }^{3}$ Other philosophers have defended views similar to Alexander's, if typically not as radical. See, e.g. Steinhoff (2013) and Vallentyne (2016). I will not address their arguments here.

${ }^{4}$ In a separate discussion of self-defense, he denies explicitly that the proportionality requirement applies to self-defense, at least given advance notice of the risk of disproportionate response (1987, p. 1181n15). In later work (Alexander and Ferzan 2009), Alexander seems to dispense with the qualification. That is, he denies that self-defense against culpable aggressors is subject to the proportionality requirement, whether or not there has been prior warning (pp. 119-122). However, his reasons for this denial seem different from those discussed in the present paper, and I will ignore them. Also, he mentions cases like those discussed in his earlier papers and in no way renounces the argument found in them (p. 118). Further, in later papers he seems to endorse his earlier argument as applied to self-defense (2016, p. 36) and punishment (2013), respectively.

5 Other than Alexander, proponents of the self-defense justification as here defined include Hurka (1982), and Quinn (1985). The latter explicitly rejects Alexander's view of proportionality, the former implicitly. On a somewhat broader definition, self-defense theories of punishment have been defended by several other writers. Prominent examples include Montague (1995), Farrell (1990) and, more recently, Tadros (2011).
} 
everyone holds that justified punishment must be preceded by a prior warning. ${ }^{6}$ As a consequence, the argument of this paper has implications for the punishment debate as well. The self-defense justification holds an important place there, as a leading deontological alternative to standard retributivism. Evidently, then, if its advocates wish to retain some sort of proportionality requirement, they must solve the puzzle of proportionality. This point is also a moral of David Boonin's trenchant critique of the self-defense justification. Strikingly, Boonin endorses Alexander's view of cases like those above, but treats them rather as a reductio ad absurdum of that justification (2008, pp. 201-202). Yet he does not consider the implications for the right to self-defense itself — which he does not question-nor the possibility that the problem is with Alexander's claims rather than with the self-defense justification. Solving the puzzle of proportionality amounts in effect to a rebuttal of this objection of Boonin's to the self-defense justification. (However, it is not relevant to Boonin's other objections. See ibid. pp. 198-201, 203-207.)

As a consequence of the above, I should note that though this paper is relevant for the punishment debate, its immediate topic is self-defense. This fact mirrors the structure of the self-defense justification, which also treats self-defense as primary to punishment.

\section{Proportionality and Authority}

The question we now face is this: why does the proportionality requirement arise, when it does? I have granted to Alexander that there are self-defensive acts, such as throwing the watch into the shark tank (Tank 1), to which the requirement does not apply. But what happens when it does apply, as many of us think it sometimes does (e.g. in Tank 2)?

Let me first state Alexander's view succinctly. He holds that the proportionality requirement fails to apply to the defender's action if the offender meets two conditions: (a) his action is wrongful (thus making him culpable), and (b) he was (made) aware of the risk he was taking. If so, I will assume, these conditions are individually necessary and jointly sufficient for justifying disproportionate (self)protective harm. ${ }^{7}$ Let us call them the 'wrongful-act condition' and the 'notice condition', respectively. I do not contest their necessity, but rather only their joint sufficiency. My strategy for answering the 'why' question is indirect. It consists of two main steps. First I ask what justifies persons in causing any self-protective harm

\footnotetext{
${ }^{6}$ A couple of caveats are in order. First, I simplify even Alexander's earlier position on punishment, which has a significant retributivist component as well. Interested readers may consult (1980, pp. 200-208) and (1986, p. 182). Second, in the book cited in note 4 above (Alexander and Ferzan 2009), Alexander has taken an explicitly desert-based retributivist view of punishment, which of course includes a proportionality requirement.

7 It will likely be objected that in treating the two conditions as jointly sufficient I overlook the familiar necessity requirement on self-defense. I omit it here as Alexander himself does not bring it up, and there are indications that he would deny that it must be included (because advance warning makes it, too, superfluous). This is perhaps not surprising, given that in a later discussion (2016, p. 34) he argues that the necessity requirement is simply part of the proportionality requirement. For reasons of space I cannot discuss this issue here.
} 
at all. Here I endorse the common view that rights provide this justification. In the second step I argue that these same rights also plausibly imply the proportionality requirement as well, by virtue of their essentially possessing strength as well. If so, however, the notice condition could not invalidate the proportionality condition without invalidating the wrongful-act condition as well, which Alexander concedes is not the case. That is what I will be arguing for in this section.

I begin with some important preliminaries. Though he is not explicit about it, Alexander tends to restrict his attention to a special class of self-defensive acts, namely those in which the defender creates a mechanical threat of harm to the offender. The two Tank cases are instances (as are most other cases that Alexander mentions). I will follow him in this. Importantly, I use the expression 'create a threat' in a somewhat technical sense. As a first approximation, I will borrow the definition due to Quinn (1985, p. 335): to create a threat against some person $x$ is 'first deliberately to create a real risk that $x$ will suffer a certain evil if he does or omits a certain specified action and second, to warn $x$ of the existence of this risk, where by these means $x$ may possibly be deterred from the act or omission'. (Later we will see that this definition must be modified.) Further, that such a threat is mechanical means that once activated, the defender lacks control over it. Hence his only morally relevant decision is the initial one of activating. It is not odd that Alexander focuses on self-defense cases involving threats, since only in them will the notice condition be met. Also, the mechanical nature of the threats he considers is hardly accidental either, as using examples involving such threats will tend to make his view look more plausible. I will get back to this point briefly in 'When Does the Proportionality Requirement Apply?' section.

As we are ultimately interested in the permissibility of the defender's action, and as we are now assuming that this action consists in the creation of a mechanical threat, we have to ask what, in general, makes such an action permissible. One common view is that the wrongness of a threat derives from the wrongness of the threatened action. ${ }^{8}$ This idea has its attractions, but it does not fit mechanical threats: in creating such a threat, after all, one does not threaten to do anything. Yet surely creating the threat could be wrong anyway-most obviously if the act triggering the harm is not wrongful. The suggested principle could perhaps be reframed to deal with this difficulty, but I choose to look for alternatives. I prefer the following account. A threat against someone is permissible if and only if it amounts to imposing a cost on, or attaching a price to, one of that person's (independently existing) options which the threatener is entitled to impose. The 'cost' we may here understand as a risk of harm, triggered by the other person's choosing the option in the teeth of the threat. This cost, it should be noted, is imposed precisely by the person creating the threat, not the person subjected to it. I will say more in 'When Does the Proportionality Requirement Apply?' section about what it is to 'impose' a cost on an option. I also stress that the account applies to threats as defined above; hence it presupposes that the notice condition is met.

\footnotetext{
${ }^{8}$ Cf. Berman (2002). Anderson (2011) criticizes Berman specifically, but it is not clear that his criticisms still apply if we use 'threat' in the special sense I employ. For an account perhaps closer to the one I advocate below, see Pallikkathayil (2011). However, her account also does not fit mechanical threats.
} 
I just said that creating a threat is justified if it amounts to imposing a cost on one of that person's options which the threatener is entitled to impose. This by itself is actually not that helpful, so we must consider the italicized clause a bit more closely. When we make a threat, mechanical or otherwise, we are in a way commanding or ordering another to perform or omit some action, on pain of 'punishment' (if only administered mechanically). For the threat to be justified, then, one must have the authority to issue such a command. Now, the kind of authority I have in mind must be understood as moral authority. It does not require any particular legal or social standing. A person could have it even in the state of nature-or so I will assume. Introducing such a notion perhaps does not explain much by itself. But it is useful to consider why it exists, when it does. What could endow a person with the authority to issue commands to others, threatening them with retaliation if they disobey, even in the state of nature? Possibly many things could, but I will here make another simplifying assumption, this time to the effect that moral rights create (or are perhaps in part constituted by) that kind of authority. This answer should be familiar. Indeed, it is part of the conception of rights as we normally understand them that they are enforceable, if not necessarily at the right holder's discretion, and that feature in turn seems to amount precisely to the authority to issue commands and threaten retaliation. Hence, the reason why we are not justified in creating a threat when the wrongful-act condition is not met is precisely that no right of ours is at stake. The wrongful-act requirement follows unproblematically. For our purposes, a wrongful act is precisely an action that violates or threatens to violate a right. Hence, such an act, or the prospect of it, gives the right holder the authority to use force and create threats.

Now, it might seem that Alexander could agree with all of the above but still maintain that it does nothing to explain the proportionality requirement. The above account tells us why the wrongful-act requirement holds, but it might seem to leave open the following possibility: any right gives its holder the authority to make any threat, and so threats are not subject to any proportionality requirement, no matter how liberal. In other words, the only authority-conferring property of a right is precisely that it is a right. Nothing else about it matters at all. But this line simply disregards what seems an essential feature of a right. In particular, a right has not only a content, but also a strength or importance. ${ }^{9}$ It is not obvious how the strength of a given right is determined, but we need no account of this matter at present. It is enough that we can say this: having a right essentially involves having something at stake, and the strength of the right corresponds in some way to the value or significance of that which is at stake for the right holder (i.e. the right's content). What authorizes the defender to make threats, then, is precisely that there is something at stake for him, important enough to be 'protected' by a right. Otherwise his threat would have been wrongful. What I am saying in defending the proportionality requirement, then, is that what authorizes a person to make this particular threat is that that particular thing is at stake for him-not that something or other, of some value or other, is at stake. To be sure, nothing very precise follows

\footnotetext{
9 Admittedly not all think of rights in that way. This is not the place to defend the view I take in the text, however.
} 
about which harms are proportionate to which right violations, so there is work left to do (though I strongly doubt that our judgments of proportionality can be more than very rough in any case). Fortunately though, for our immediate purposes this problem does not much matter.

To bolster the reasoning in the preceding paragraph, I note that the denial of proportionality is remarkably out of tune with the way we look at rights in other contexts. Consider how the strength of a right helps determine what exactly that right gives us the authority to demand of others, in two respects. In the first place, others are required to sacrifice more to avoid infringing our (negative) rights not to suffer harm. And the stronger our rights, the more they are required to give up. Secondly, others are required to $d o$ more to protect our important rights than they are to protect our less important rights. Thus, if one person's (positive) right gives him the authority to demand assistance, the scope of that authority depends on the strength of his right. ${ }^{10}$ The stronger the right, the more he is authorized to demand. Now, there is no reason why the two cases - the sacrifice or effort we can demand and the harm we can threaten or impose-should be given radically different treatments. The exact relationship between these two magnitudes is a different issue. What matters at present is simply that right strength makes an important difference in both contexts, that is, both when we determine what $A$ is required to do in preventing himself from violating $B$ 's right and when we determine what $B$ is permitted to do to $A$ in order to prevent that same wrong.

Could Alexander reply that the conclusion to draw from the above analogy is the reverse of the one I urge? That is, could he contend that a right's strength also makes no difference to what it allows us to demand of others? If such a claim were true, it is not clear that there is any point in talking about the 'strength' of a right in the first place. While such a radical move could perhaps not simply be dismissed out of hand, surely we would need very strong reasons for accepting it, reasons that Alexander has not supplied.

Alexander is, I suspect, more likely to make another objection, namely that I have failed to observe the distinction between innocent and culpable persons. I said just now that "there is no reason why the two cases-the sacrifice or effort we can demand and the harm we can threaten or impose-should be given radically different treatments'. But there is a difference between them, namely that the sacrifice or effort is (let us grant) demanded of some innocent person, but the harm is imposed on a culpable person. Alexander could maintain that this difference is crucial and explains why the notion of proportionality has a place in one context but not the other.

In response we may note a couple of things. In the first place-though Alexander might perhaps beg to differ-this distinction between culpable and innocent persons does not seem to invalidate the point that the harm we are required to suffer ourselves to avoid infringing other people's rights depends on which these rights are. If I am culpable for finding myself in a situation in which I am forced to choose between suffering harm myself and infringing another's right, I am no doubt required to suffer greater harm to avoid infringing that right than I would have been

$\overline{{ }^{10} \text { Admittedly not all accept positive rights. See the preceding note. }}$ 
otherwise, but it is not as if my culpability makes the importance of what is at stake simply go away. No matter my degree of culpability, I am not required to commit suicide by driving my car over a cliff rather than running over your garden gnome. But secondly, and more importantly, Alexander's suggested response in terms of culpability begs the question. No doubt the offender in a case of self-protection is culpable, but the question is 'culpable of what'? The response simply assumes that the answer to that question is irrelevant, so it does not advance the discussion. It assumes, in other words, either that one could not become more culpable by violating a stronger right, or at least that such differences in degree of culpability do not matter to what we are entitled to do in defense of our rights.

To sum up, both the wrongful-act and proportionality requirements apply because persons have the authority to threaten others in virtue of having rights that these same threats enforce, such that the scope of the authority in a given case is determined by the content and strength of the relevant right. In the final step of the argument, as indicated earlier, we note that if advance warning cannot invalidate the wrongful-act condition, as Alexander agrees, then it should not be able to invalidate the proportionality condition either, as the latter has the same ground.

\section{The Responsibility Argument}

I have now stated my own reasons for denying that the notice condition invalidates the proportionality requirement. In this section I wish to consider an argument for thinking otherwise that may be attributable to Alexander, though it is not explicit in his writings, one that goes beyond appeal to intuitions about cases like Tank 1 and Tank $2 .{ }^{11}$ The underlying idea is that if the offender knowingly runs the risk imposed by the defender's threat, meaning that the notice condition is met, the responsibility for that risk, and so for whatever harm results, is his own. When I say that a person is 'responsible for' some harm I mean that that harm is his fault. That notion in turn may require some elucidation, but here I will have to presuppose an 'intuitive understanding'. In any case, the argument can be framed as follows, with three premises:

Responsibility: The offender is responsible for the harm he himself suffers if the wrongful-act and notice conditions are satisfied.

Exclusion: In cases of the kind that interest us, either the offender is responsible for the harm he suffers, or the defender is, but not both.

Applicability: A self-protective action $A$ is impermissible because disproportionate only if the defender is responsible for the harm the offender suffers as a result of $A$.

$\therefore$ If the wrongful-act and notice conditions are satisfied with respect to a given self-protective action, that action is not impermissible because disproportionate (and so the proportionality requirement does not apply to it).

11 Alexander rarely talks about responsibility for the harm the offender suffers, but see (1980, p. 218). 
Call this the 'responsibility argument'.

What I said in the preceding section should already make us suspicious of this argument. In effect, it tells us that advance warning invalidates the proportionality requirement precisely by shifting responsibility for the offender's harm to the offender himself. But if, as I argued in 'Proportionality and Authority' section, the ground of the proportionality condition is the same as that of the wrongful-act condition, and the notice condition does not invalidate the wrongful-act condition, as Alexander certainly grants, it should not invalidate the proportionality condition either. On my diagnosis, the above argument leads us astray because it focuses our attention exclusively on the offender's harm, rather than the original threat. That way, the question of whose fault that harm is tends to predominate, and along with it the idea that the defender's advance notice shifts responsibility to the offender, exculpating the defender. The culprit, I believe, is Applicability, as should become clear once we remember that we are now concerned particularly with the special case of mechanical threats. (I will not contest Exclusion. For a possible problem with Responsibility, see the next section.) I am prepared to allow that the defender, having created a mechanical threat, need not be responsible for the harm the offender suffers after having ignored the threat. But that does not mean that this threat was not unjustified to begin with, if it was disproportionate. Causing actual harm is not necessary for proportionality to be an issue: creating a threat of harm is sufficient. Remember what I said in 'Proportionality and Authority' section: in creating a threat, the defender 'imposes a cost' on one of the offender's options. That cost, meaning a risk of harm, is attached to the option whether or not the offender chooses it. Hence, we should reject Applicability, and the argument fails.

\section{When Does the Proportionality Requirement Apply?}

We turn now to the question of when the proportionality requirement applies (meaning to which self-protective acts it applies). I have agreed with Alexander on two counts: that the requirement does apply if the notice condition is not met and that it does not apply in Tank 1. But I have also challenged his claim that it does not apply in Tank 2. I have already explained why I believe the requirement applies when it does apply, and intend in this section to use that answer to distinguish the two Tank cases. I wish first to criticize an earlier answer which I believe is unsuccessful and will then turn to my own favored solution.

\section{The Last-Action Condition}

To my knowledge, the only attempt in the literature to draw the line between those cases in which the proportionality requirement applies and those in which it does not is due to Nino (1986, p. 184). It takes its lead from a certain familiar view about causality. In their influential analysis of that notion, Hart and Honoré write: 'A deliberate human act is...most often a barrier and a goal in tracing back causes...it is often something through which we do not trace the cause of a later event and something to which we do trace the cause through intervening causes of other kinds' 
(1985, p. 44; original emphases). In particular, we usually treat the last action in a series of events that includes several actions as the cause of a given outcome, even if other earlier actions in the series were also necessary for that outcome. We can apply this idea to our present problem if we frame it as a thesis about responsibility rather than causality. Specifically, we can use it to weaken the premise Responsibility of the responsibility argument in 'The Responsibility Argument' section by adding a further 'last-action' condition to Alexander's two conditions:

Weak Responsibility: The offender is responsible for the harm he himself suffers if the wrongful-act and notice conditions are satisfied and the last action in the series of actions leading to the harm was his.

If this weaker version is substituted for the original, and even if we grant the questionable premise Applicability, the resulting argument no longer goes through in those cases in which the defender, rather than the offender, acts last. This is true of standard cases of self-defense (and of punishment). Further, we could also conclude that the proportionality requirement does apply in such cases, even if the notice condition is met, pace Alexander, if we combine Weak Responsibility and Exclusion with the following thesis:

Converse Applicability: If the defender is responsible for the harm the offender suffers as a result of a self-protective action $A$, then the proportionality requirement applies to $A$.

Alexander has said nothing to cast doubt on this last thesis, and I will grant it. Finally, the modified responsibility argument (with Weak Responsibility substituted for the original Responsibility) does go through in Tank 1, so Alexander's view of that case would also be vindicated.

This strategy fails, for while it can indeed distinguish between Tank 1 and typical cases of self-defense (or punishment), in which the defender acts last, it cannot distinguish Tank 1 from Tank 2, which is what we want. In the latter case, remember, the defender puts the sharks into the tank himself, to protect the watch. If the offender dives into the tank thereafter and is harmed, his action came last. But then the same modified version of Alexander's argument just used to show that the proportionality requirement does not apply to the defender's action in Tank 1 draws the same conclusion about Tank 2. Yet I maintain-pace Alexander-that it is wrong to use such drastic means of defense, and that this wrongness is due precisely to the excessiveness of the harm threatened relative to the right protected. As I noted above, the question we need to ask here is not that of whose fault the offender's harm is, but rather that of whether the defender's threat was justified to begin with.

It may be objected that this failure to distinguish Tank 1 and Tank 2, though perhaps an embarrassment, is tractable as long as it remains possible to distinguish both of these, involving mechanical threats, from standard self-defense cases. After all, my preoccupation with drawing the line between the two Tank cases is due in the first place to my simply having assumed, in the introduction, that if the proportionality requirement does not apply in Tank 2, then it does not apply in other cases either. As an illustration of such an 'other' case, consider 'Tank 3', in which the defender lets the sharks in from an adjacent tank, Bond-villain style, only after 
the offender has already jumped in. But what if my initial assumption is false? Well, I confess to feeling the allure of using the last-action criterion to distinguish Tank 2 and Tank 3. Indeed, and as I intimated in 'Proportionality and Authority' section, it is no accident that Alexander cites cases involving mechanical threats in support of his view, for in them the offender will seem more 'responsible' than in many cases in which the defender 'acts last' (as, perhaps, in Tank 3). Yet there remains something unsatisfactory about trying to draw the line we want between Tank 2 and Tank 3, rather than between Tank 1 and Tank 2. After all, if we grant in the first place that there is no proportionality requirement in Tank 2, that will presumably be because we hold the offender responsible for the harm he suffered: he 'knew what he was doing' and 'has to take his chances'. Yet the defender's 'acting last' does not alter that fact about the case. If it is decisive when the offender acts last, why not also when the defender does? Simply appealing to the Hart/Honore analysis of causation, plausible though it may be in itself, is unconvincing. At the very least it would be comforting to have recourse to an alternative account that pre-empts the problem by giving a justification for not granting in the first place that the proportionality requirement does not apply in Tank 2.

\section{The Appeal to Cost Imposition}

We find a more promising approach to answering the 'When?' question, including drawing the line between the Tank cases, by returning to the notion of a wrongful threat introduced in 'Proportionality and Authority' section. Remember, I said that a person $A$ who creates a threat against another person $B$, whether in self-protection or otherwise, thereby imposes a cost on one of $B$ 's options, and informs B about the danger. $A$ acts wrongly when that cost is wrongfully imposed. Once we attend to this notion of a wrongful threat, we will find that the question of who is responsible for the offender's harm, though certainly still important, is not all-important. Let me explain. To begin with, I have agreed that Alexander's notice condition is necessary for justifying a disproportionate response. In other words, if that condition is not met, the proportionality requirement applies. Further, surely the reason why advance warning has this effect is because it matters to responsibility. Simplifying a bit: if the offender does not know that he risks harm, the responsibility for any such harm must be the defender's, not his. At least that is so if he could not be expected to know of the risk he faces, which will typically be the case if the harm is disproportionate (though he may be expected to know, even without warning, that the defender may cause defensive harm of some magnitude). If you will, we could say that we then apply the proportionality requirement 'directly' to the harm actually caused, because it is the defender's responsibility.

But then what happens if the notice condition is met and the offender does know of the risk he faces? Now recall my analysis of the responsibility argument in 'The Responsibility Argument' section. I did not dispute that the offender in such a case is responsible for the harm he suffers. Hence we could not, in the phrase I just used, apply the proportionality requirement directly to this harm, as it is not the defender's responsibility. To that extent, then, Alexander is right. But I also noted that the argument errs by overlooking the possibility that it is wrong to create a mechanical 
threat even if the offender is ultimately responsible for the harm he suffers, if the threat is disproportionate. After all, even if the defender is not responsible for the harm that results if the offender triggers the mechanical threat, surely he is responsible for the threat itself, and thus for the cost that it imposes on one of the offender's options. Hence, the proportionality requirement could still apply, but indirectly as it were, to the threat of harm, rather than (or possibly in addition to) the resulting harm (if any). Applied to threats, the proportionality requirement is a demand that the cost imposed by the threat and the harm prevented by the imposition be proportionate, where that demand in turn holds because the defender has a right of a certain strength. (Again we can leave aside exactly what counts as 'proportionate' to what in this context.)

Armed with this understanding of how the proportionality requirement applies to threat creation, when the notice condition is met, we may return to the two Tank cases. For we are now able to conclude that if the defender's threat creation in these cases does not count as imposing a cost on one of the offender's options in the first place, there is nothing there for the proportionality requirement to work with, and so it does not apply. This observation is the key to distinguishing the two cases, as I will now show.

The first order of business is to consider a little more closely what is involved in the defender's imposing a cost on one of the offender's options. I suggest the following account of that notion:

The defender's act $A$ imposes a cost on an independently existing option $O$ of the offender's if and only if

(i) $A$ makes it true that if the offender were to (try to) realize $O$, then he will suffer a risk of harm; and

(ii) the offender's doing $O$ qualifies as the cause of his coming to harm (or at least his suffering an increased risk of harm).

As I will show presently, while the defender's act of putting sharks in the tank in Tank 2 satisfies both of these conditions, his act of throwing the watch into the tank in Tank 1 satisfies only the first. Hence, we distinguish the cases as desired.

Let me add a few words in explanation of the two conditions. In the first place, note that option $O$ has to be 'independently existing', meaning that it would have existed anyway, even if $A$ had not occurred. Perhaps that much is implicit in saying that $A$ 'imposes a cost' on $O$, but it does not hurt to make the point explicit. As a consequence, I will assume that imposing a cost on an option means making it more dangerous than it otherwise would have been. Second, condition (i) merely says that $A$ has made true a certain (subjunctive) conditional, one that would otherwise have been false. It does not entail (ii). This will become clear as we go along. Third, I can only offer a partial account of the notion of a cause. In particular, I will say that a cause should be a necessary condition of its effect. To be sure, that idea is only approximately true, due to the phenomenon of overdetermination, but I will here simplify by disregarding such cases. (It may indeed also be true that, typically at least, an action counts as a cause only if it comes last—-see above-but I will not rely on that idea specifically.) The notion of causation is used not only in (ii), in 
which the word 'cause' appears explicitly, but also in (i), through the words 'makes' and 'realize'. In particular, then, for $A$ to make the conditional true it has to be a necessary condition of its being true. Hence, to tell whether $A$ does make the conditional true, we have to compare the situation that would obtain if $A$ is performed with the situation that would obtain if it is not performed, other things being equal. In Tank 1, for instance, we must compare the situation in which the watch is in the tank, but with the sharks in it, with the situation in which the watch is not in the tank but the sharks still are.

I need to do two things to justify my response to Alexander's challenge. The first is to vindicate the analysis of 'imposing a cost' just proposed; the second is to distinguish the Tank cases on the basis of that analysis. As far as the first task is concerned, I take for granted that condition (i) is indeed necessary for cost imposition-I cannot see how this could be denied. The challenge, then, is to explain why it is not sufficient, that we need (ii) as well. ${ }^{12}$ My procedure here will be to identify an action that clearly meets condition (i) but arguably does not count as imposing a cost on any of the offender's independently existing options. Then I will attempt to explain this latter fact about it by appeal precisely to its failure to meet condition (ii). The action I choose to make my point is the defender's throwing the watch into the tank in Tank 1 . To see that it indeed meets condition (i), we may note that there is an independently existing option $O$ of the offender's-namely stealing the watch (or trying to steal it) — such that the defender's action has made it true that the offender risks harm if he does $O$. Or, at any rate, so we may assume: had the defender not thrown the watch into the tank, the offender could have stolen it without risk to himself. (If we want to, we can stipulate that the watch would then have been in the defender's pocket.)

Having shown that the defender's action in Tank 1 does meet condition (i), we turn to ask whether it makes any of the offender's (independently existing) options more dangerous (which, as I noted above, is what its 'imposing a cost' on an option amounts to). While it is perhaps difficult to prove that there is no such option, it is certainly hard so see what it could be. It could not be that of diving into the tank. Surely that option is no more dangerous than it would have been otherwise. ${ }^{13}$ If it is option $O$, not even condition (i) would be met. Indeed, the only obvious candidate for an option that has been made more dangerous is precisely that of trying to steal the watch. However, though we may be inclined to agree that the defender's action has made that option more dangerous, that appearance is due entirely to our simply presupposing that, once the watch is in the tank, the offender tries to steal it precisely by diving into the tank - as opposed to whatever method he would have employed otherwise (e.g. picking the defender's pocket). If anything, then, in agreeing that the option of trying to steal the watch is dangerous once the watch is in the tank, we are saying that something like the option of trying to steal the watch by

\footnotetext{
12 I will actually not argue that that (i) and (ii) are jointly sufficient. As far as my disagreement with Alexander is concerned, what matters is that (ii) is also necessary.

13 But what if it is more dangerous than it would have been otherwise (perhaps because the presence of the watch, for some reason, makes the sharks more aggressive)? That seems to make the case more similar to Tank 2, and the notion that the proportionality requirement applies to the case correspondingly more plausible.
} 
diving into the tank is dangerous. But that option also has not become more dangerous by the defender's action, nor would it help meet condition (i). Indeed, the option of trying to steal the watch, simpliciter, could not helpfully be said to have been made more dangerous; for it does not have any definite consequences at all, unless the method of stealing be specified.

Taking it as established, then, that the defender's action of throwing the watch into the tank in Tank 1 meets condition (i) but fails to impose a cost on any of the offender's options, my next task is to show that this fact is best explained by that action's failing to meet condition (ii). As we have seen, the reason why the offender's trying to steal the watch-which, again, seems to be the only option of his that could make the defender's action meet condition (i) - has not been made more dangerous by the defender's action is its lack of definite consequences. The way to remedy that problem, then, and to ensure that $O$ has definite, and relevant, consequences is precisely to add condition (ii), that $O$ cause the offender's harm. Further, it is clear that his trying to steal the watch is not the cause of the offender's harm in Tank 1, for it is not a necessary condition of that harm. Rather, the cause is surely his diving into the tank. The same harm would have resulted if he had dived into the tank without trying to steal the watch, but not if he had tried to steal the watch without diving into the tank (perhaps by trying to pick the defender's pocket instead).

I should add that there is another way of strengthening condition (i) to achieve the result we want, without condition (ii), and so with less apparent emphasis on the potentially problematic notion of a cause. To see it, note that in Tank 1, while there are many ways in which the offender could try to steal the watch, the defender's action has failed to make condition (i) hold with respect to any of them. I noted that trying to steal the watch by diving into the shark tank is no more dangerous after the defender's action. The same presumably goes for trying to steal the watch by picking the defender's pocket, and so on. But if the defender has not made condition (i) hold with respect to any of the ways in which the offender could realize option $O$, then how could he have done so with respect to $O$ itself? The suggestion, then, is that we strengthen (i) into:

(i*) there is some way $W$ of realizing $O$ such that $A$ makes it true that if the offender were to (try to) realize $O$ in $W$, then he will suffer a risk of harm

To be sure, $\left(\mathrm{i}^{*}\right)$ in effect presupposes some understanding of what counts as a 'way' of doing something. I have no worked-out account of this notion-and perhaps in the end we would in any case have to rely on that of a cause to make sense of it. I observe only that any such account which allows that the defender has made condition (i) hold of some 'way' of stealing the watch in Tank 1 will likely strike us as artificial. ${ }^{14}$

\footnotetext{
${ }^{14}$ Offhand the most effective formulation would be something along the lines of 'the way which is most likely to be successful'. However, this description is naturally taken to refer to distinct 'ways' before and after the defender's action, and so ( $\left.i^{*}\right)$ is not met-though again I rely on a method for individuating 'ways' which I have not provided.
} 
Be that as it may, and returning to the original proposal, it is now easy to distinguish the two Tank cases. We have already seen that in Tank 1, the defender's action of throwing the watch into the tank does not meet condition (ii) - though it does meet condition (i). By the same token, though, the defender's action in Tank 2 of putting sharks into the tank does meet condition (ii): it makes an option of the offender's more dangerous, namely that of diving into the tank (and also, for that matter, that of trying to steal the watch by diving into the tank). If the offender were to dive into the tank and suffer harm, or risk of harm, the cause of that harm is precisely his having dived into the tank (or, perhaps, his having tried to steal the watch by diving into the tank). Hence we have a ground for saying that the defender in Tank 2 does impose a cost on one of the offender's options and hence that the proportionality requirement applies in that case, but not in Tank 1. As I said, the requirement demands that cost imposed and harm prevented be proportionate (albeit vaguely speaking).

I also hold that the distinction I have described corresponds to the one mentioned in the introduction, between creating a threat and merely exploiting one-if only with the proviso that the new threat be triggered by an independently existing option of the offender's. That is, if such a distinction can be drawn at all-and I take for granted that it can-it will match the one between the defender's making it the case that some action of the offender's causes a harm (or risk of harm) and the defender's merely making true the following conditional: if the offender were to do a certain thing (such as trying to steal the watch), then he will suffer a risk of harm. At any rate, if merely making the conditional true were enough for the defender's action to count as creating a threat, it is not clear what merely exploiting one would amount to, if it is indeed distinct. (Note that I now presuppose a stronger notion of a 'threat' than the one borrowed from Quinn in 'Proportionality and Authority' section, which employs only the conditional and makes no mention of causality. As should be clear, the strengthening is an improvement.)

The above should serve to distinguish the two Tank cases in a way that generalizes to other similar pairs of cases. Objections to the proposed distinction are likely to be aimed at showing it to be overly subtle. Whatever our view of the two Tank cases, this objection runs, the proposal is bound to treat differently cases that are intuitively on a par-and hence the proposed distinction does not generalize after all, even if we grant that it makes sense in the Tank cases. To take just one example of this kind, what is the difference between installing a machine gun in my house to deter trespassers and building the house around an existing gun (or moving my existing house to where the gun is) $?^{15}$ I could not respond to all such cases in detail. Remaining at the general level, I note my opinion (which Alexander would of course reject) that a subtle distinction between the two cases is better than none; and also that that distinction, if it exists at all, is bound to be subtle. Had there been an immediately apparent way of drawing the line, Alexander's reasoning would not have had any appeal to begin with. More importantly, though, I repeat my main point, that what makes the proportionality condition apply is precisely that the defender has imposed a cost on one of the offender's options, against which

\footnotetext{
15 An anonymous referee suggested this case.
} 
proportionality can be assessed, and that the best account of that notion in turn relies on the idea of the realization of that option as the cause of harm or risk of harm. This analysis is applicable to the house case just as it is to the Tank cases. Only in the first version of the house case, in which the gun is added later, has an option with definite consequences become more dangerous-namely that of breaking-into-thehouse-located-at-such-and-such-a-place. (In this case, the method of entry perhaps makes no difference to how dangerous the action is). By contrast, the option of breaking-into-the-house-wherever-it-may-be does not have definite consequences and so cannot be said to have been made more dangerous. By the same token, and supposing the house was moved from location $L_{1}$ to location $L_{2}$, neither the option of breaking-into-the-house-at $-L_{1}$ nor the option of breaking-into-the-house-at $-L_{2}$ could usefully be said to have been made more dangerous.

Let me end by mentioning a qualification to the above account. It has to do with those special cases in which the defender counts as exploiting a threat rather than creating one, but the threat he exploits is one he himself has created earlier. ${ }^{16}$ For instance, in a variant of Tank 1, the defender throws the watch into a tank with sharks he himself put there earlier. In some versions of this case we might be tempted to say that the defender has made an option of the offender's more dangerous, and specifically the option of stealing the watch, not simply by throwing the watch into the tank, but rather by the composite act of first putting sharks in the tank and later throwing the watch into it, in which case the proportionality requirement should apply to that composite act (and, presumably, to his later act of throwing the watch into the tank as a part of the composite). Whether we want to describe the case in that way may depend on the defender's intention in first putting sharks into the tank. If he did it precisely with a view to using the sharks later to protect his watch or other property, we would be more likely to think of him as having performed a composite act to which the proportionality requirement applies. On the other hand, if the first act had no defensive purpose, we would be less likely to take that attitude. I concede, though, that these cases are difficult. The role of the defender's intention would need further study, that may in turn force us to revise some of what I say above. But that is a matter for another day.

Summing up, I have accomplished what I set out to do, namely to answer two questions: why does the proportionality requirement exist, and when does it arise? Alexander's challenge to the proportionality requirement is thereby met, as is the objection to the self-defense justification of punishment that depends on accepting that challenge.

Acknowledgements I gratefully acknowledge a grant from the Swedish Crime Victims Fund (Grant\# 09280/2009) which made work on this paper possible.

Open Access This article is distributed under the terms of the Creative Commons Attribution 4.0 International License (http://creativecommons.org/licenses/by/4.0/), which permits unrestricted use, distribution, and reproduction in any medium, provided you give appropriate credit to the original author(s) and the source, provide a link to the Creative Commons license, and indicate if changes were made.

${ }^{16} \mathrm{I}$ am indebted to Wlodek Rabinowicz for raising this issue. 


\section{References}

Alexander, L. 1980. The Doomsday Machine: Proportionality, Punishment and Prevention. The Monist 63: $199-227$.

Alexander, L. 1986. Consent, Punishment, and Proportionality. Philosophy \& Public Affairs 15: 178-182. Alexander, L. 1987. Justification and Innocent Aggressors. Wayne Law Review 33: 1177-1189.

Alexander, L. 1991. Self-Defense, Punishment, and Proportionality. Law and Philosophy 10: 323-328.

Alexander, L. 2013. Can Self-Defense Justify Punishment? Law and Philosophy 32: 159-175.

Alexander, L. 2016. Recipe for a Theory of Self-Defense. In The Ethics of Self-Defense, eds. C. Coons and M. Weber. Oxford: Oxford University Press.

Alexander, L. and Ferzan, K. K. (with S. Morse). 2009. Crime and Culpability. Cambridge: Cambridge University Press.

Anderson, S. A. 2011. On the Immorality of Threatening. Ratio 24: 229-242.

Berman, M. N. 2002. The Normative Functions of Coercion Claims. Legal Theory 8: 45-89.

Boonin, D. 2008. The Problem of Punishment. Cambridge: Cambridge University Press.

Farrell, D. 1990. The Justification of Deterrent Violence. Ethics 100: 301-317.

Hart, H. L. A., and T. Honoré. 1985. Causation in the Law, 2nd edn. Oxford: Oxford University Press.

Hurka, T. 1982. Rights and Capital Punishment. Dialogue 21: 647-660.

Montague, P. 1995. Punishment as Societal-Defense. Lanham, MD: Rowman \& Littlefield.

Nino, C. S. 1986. Does Consent Override Proportionality? Philosophy \& Public Affairs 15: 183-187.

Pallikkathayil, J. 2011. The Possibility of Choice: Three Accounts of the Problem with Coercion. Philosophers' Imprint 11: 16.

Quinn, W. 1985. The Right to Threaten and the Right to Punish. Philosophy \& Public Affairs 14: 327-373.

Steinhoff, U. 2013. Rodin on Self-Defense and the 'Myth' of National Self-Defense: A Refutation. Philosophia 41: 1019-1023.

Tadros, V. 2011. The Ends of Harm. Oxford: Oxford University Press.

Vallentyne, P. 2016. Defense of Self and Others Against Culpable Rights Violators. In The Ethics of SelfDefense, eds. C. Coons and M. Weber. Oxford: Oxford University Press. 